\title{
Optimization of Chemical Deposition of HgSe films
}

Martyn Sozanskyi, Vitalii Stadnik, Pavlo Shapoval, Marta Laruk, Yosyp Yatchyshyn

Department of Physical, Analytical and General Chemistry, Lviv Polytechnic National University,

UKRAINE, Lviv, S. Bandera Street 12, E-mail: martyn.a.sozanskyi@lpnu.ua

Abstract- The process of HgSe films synthesis by a chemical deposition method, has been investigated. The optimized synthesis parameters were determined by gravimetric measurements. The phase composition, optical properties and surface morphology of $\mathrm{HgSe}$ films were studied.

Keywords - mercury selenide, thin films, chemical deposition, optical properties, morphology analysis

\section{Introduction}

Mercury selenide $(\mathrm{HgSe})$ is one of the least-studied of $\mathrm{A}^{\mathrm{II}} \mathrm{B}^{\mathrm{VI}}$ group thin films materials. Mercury chalcogenides can be use in IR detectors, ultrasonic transducers, catalysts, electrostatic reflective materials and solar cells due to their unique properties $[1,2]$. Development of simple, low-cost and reproducible technique for the synthesis of mercury selenide films is an actual task.

\section{Experimental}

The chemical bath deposition of $\mathrm{HgSe}$ films was conducted with the initial working solution, consisted of mercury(II) nitrate $\left(\mathrm{Hg}\left(\mathrm{NO}_{3}\right)_{2}\right)$, sodium thiosulfate $\left(\mathrm{Na}_{2} \mathrm{~S}_{2} \mathrm{O}_{3}\right)$, as a complexing agent, sodium selenosulfate $\left(\mathrm{Na}_{2} \mathrm{SeSO}_{3}\right)$, as a chalcogenizing reagent and trisodium citrate $\left(\mathrm{Na}_{3} \mathrm{C}_{6} \mathrm{H}_{5} \mathrm{O}_{7}\right)$, as a $\mathrm{pH}$ regulator. The concentration of the $\mathrm{Hg}\left(\mathrm{NO}_{3}\right)_{2}$ in the working solution was $0.0025-0.015 \mathrm{M}$; $\mathrm{Na}_{2} \mathrm{~S}_{2} \mathrm{O}_{3}-0.1-2.0 \mathrm{M} ; \mathrm{Na}_{2} \mathrm{SeSO}_{3}-0.0025-0.025 \mathrm{M} ; \mathrm{Na}_{3} \mathrm{C}_{6} \mathrm{H}_{5} \mathrm{O}_{7}-0.0025-0.03 \mathrm{M}$. The synthesis duration was 20-220 min, temperature - 273-313 K. The synthesis of HgSe films was carried out on preliminarily cleaned square shape glass substrates of $64.80 \mathrm{~cm}^{2}$ in total area.

The phase composition of the HgSe films was investigated by diffractometer DRON-3.0, $\left(\mathrm{CuK \alpha} \alpha^{-}\right)$. Transmission optical spectra of the HgSe films were obtained on a spectrophotometer XION 500 (Dr.Lange). The investigation of the films surface morphology was performed on Atomic Force Microscope (AFM) MultiMode Nanoscope IIIa (Bruker). Elemental analysis of films was carried out on X-ray fluorescence spectrometer ElvaX Light SDD (Elvatech).

In order to optimize the synthesis process, the gravimetric measurements were carried out. The mass of deposited HgSe films were recalculated to the unit of the substrate area. For this purpose, the differences of substrates mass before and after deposition has been measured and the differences in mass were calculated. The weighing of the samples were carried out with the use of Radwag AS 220.R2 analytical weight (accuracy - $0.0002 \mathrm{~g}$ ) depending on the concentrations of initial reagents in the working solution, the synthesis duration and temperature.

\section{Results and discussion}

The X-ray analysis of HgSe films has been held. Peaks that corresponded to the cubic phase of zincblende (sphalerite) structure were identified on diffractogram.

The optical transmission $\mathrm{T}(\lambda)$ of $\mathrm{HgSe}$ films were investigated for wavelengths from 340 to $900 \mathrm{~nm}$. The increasing of the light transmission are present at $\sim 450 \mathrm{~nm}$ region. The spectral dependences in $(\alpha \cdot h v)^{2}$ vs. $h v$ coordinates allow to determine the values of fundamental absorption edge. The optical band gaps of the $\mathrm{HgSe}$ films are localized in the ranges $1.38-2.50 \mathrm{eV}$.

AFM studies of the surface morphology of $\mathrm{HgSe}$ films, showed that coating is solid and homogeneous. The coatings surface are packed of irregular shape particles. Their size innceases with increasing of deposition duration. 
The microanalysis of the HgSe films surface shows nearly stoichiometric atomic ratios of mercury to selenium with a slight excess of Se atoms.

By gravimetric measurements of deposited $\mathrm{HgSe}$ films, the dependences of mass changes on the synthesis conditions were constructed. The research results are presented in Fig. 1. The optimized synthesis parameters were found by greatest $\mathrm{HgSe}$ film mass on the each dependence.

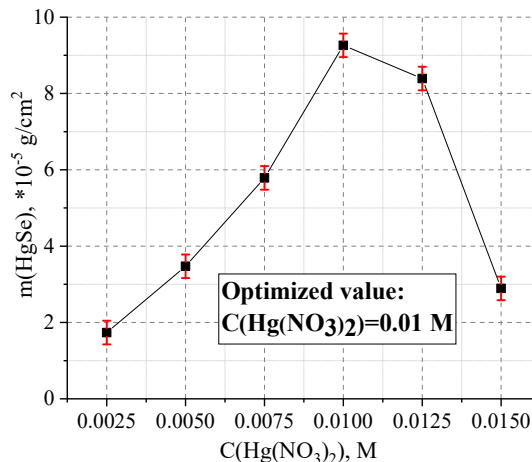

a

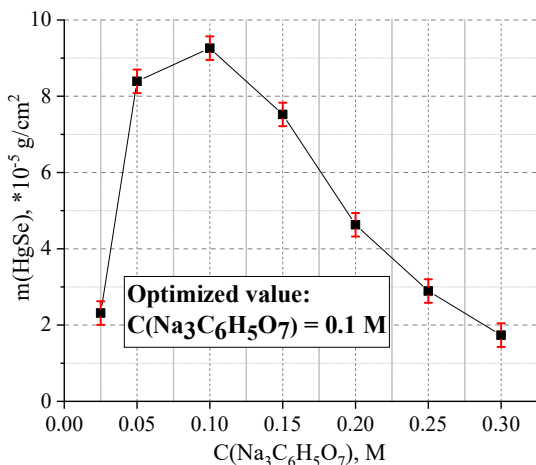

d

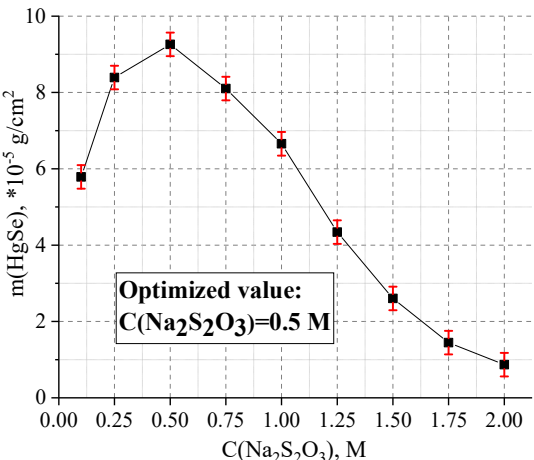

b

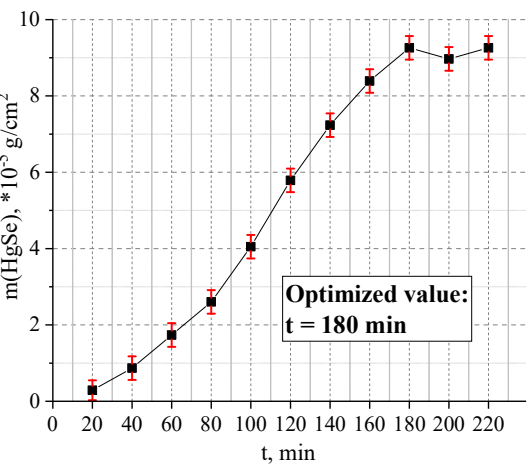

$\mathrm{e}$

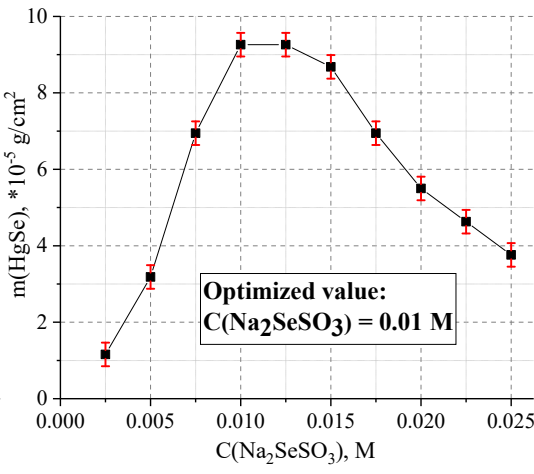

C

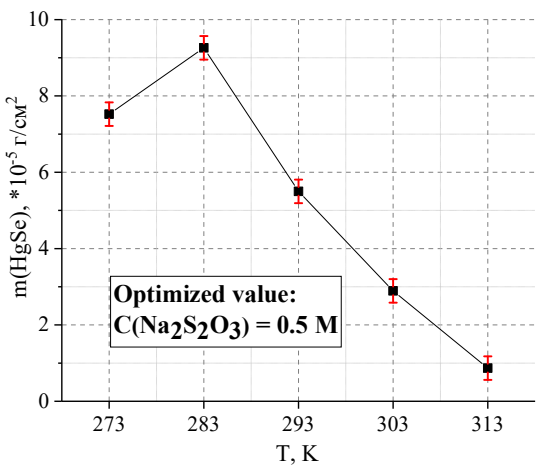

f

Fig.1. Dependences of films mass changes of $\mathrm{HgSe}$ per unit of substrate area on the concentration of: $\mathrm{a}-\mathrm{Hg}$-containing salt, $\mathrm{b}-\mathrm{Na}_{2} \mathrm{~S}_{2} \mathrm{O}_{3}, \mathrm{c}-\mathrm{Na}_{2} \mathrm{SeSO}_{3}, \mathrm{~d}-\mathrm{Na}_{3} \mathrm{C}_{6} \mathrm{H}_{5} \mathrm{O}_{7}$, $\mathrm{e}$ - synthesis duration, $\mathrm{f}-$ temperature of synthesis.

\section{Conclusion}

The HgSe films were synthesized by chemical deposition method. The optimal synthesis parameters are found. They are follows: concentration of mercury salt, trisodium citrate, sodium thiosulfate and sodium selenosulfate in the working solution $-0.01 \mathrm{M}, 0.1 \mathrm{M}, 0.5 \mathrm{M}, 0.01 \mathrm{M}$, respectively, $283 \mathrm{~K}$ of temperature and $180 \mathrm{~min}$ of synthesis duration. The phase composition, optical properties and surface morphology of $\mathrm{HgSe}$ films were studied.

\section{Acknowledgments}

This research is under the project "Thin Film Semiconductor Materials for Photo Sensitive Solar Cells” (State Registration № 0117U004455).

\section{References}

[1] M. Bazarganipour, M. Sadri, D. Davar, M. Salavati-Niasari, "Mercury selenide nanorods: Synthesis and characterization via a simple hydrothermal method," Polyhedron, vol. 30, iss. 3, pp. 1103-1107, 2011.

[2] M. Esmaeili-Zare, M. Salavati-Niasari, A. Sobhani, "Simple sonochemical synthesis and characterization of HgSe nanoparticles," Ultrasonics Sonochemistry, vol. 19, iss. 5, pp. 1079-1086, 2012. 